\title{
Biodegradation of total petroleum hydrocarbons in contaminated soils using indigenous bacterial consortium
}

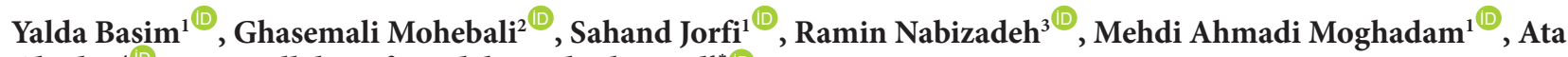 \\ Ghadiri $^{4}$, Nematollah Jaafarzadeh Haghighi Fard ${ }^{1 *}$ \\ ${ }^{1}$ Environmental Technologies Research Centre, Ahvaz Jundishapur University of Medical Sciences, Ahvaz, Iran \\ ${ }^{2}$ Microbiology and Biotechnology Research Group, Research Institute of Petroleum Industry, Tehran, Iran \\ ${ }^{3}$ Department of Environmental Health Engineering, School of Public Health, Tehran University of Medical Sciences, Tehran, Iran \\ ${ }^{4}$ Department of Immunology, School of Medicine, Ahvaz Jundishapur University of Medical Sciences, Ahvaz, Iran
}

\begin{abstract}
Background: Biodegradation of hydrocarbon compounds is a great environmental concern due to their toxic nature and ubiquitous occurrence. In this study, biodegradation potential of oily soils was investigated in an oil field using indigenous bacterial consortium.

Methods: The bacterial strains present in the contaminated and non-contaminated soils were identified via DNA extraction using 16S rDNA gene sequencing during six months. Furthermore, total petroleum hydrocarbons (TPH) were removed from oil-contaminated soils. The TPH values were determined using a gas chromatograph equipped with a flame ionization detector (GC-FID).

Results: The bacterial consortium identified in oil-contaminated soils (case) belonged to the families Halomonadaceae (91.5\%) and Bacillaceae $(8.5 \%)$, which was significantly different from those identified in non-contaminated soils (control) belonging to the families Enterobacteriaceae (84.6\%), Paenibacillaceae (6\%), and Bacillaceae (9.4\%). It was revealed that the diversity of bacterial strains was less in oil-contaminated soils and varied significantly between case and control samples. Indigenous bacterial consortium was used in oil-contaminated soils without need for amplification of heterogeneous bacteria and the results showed that the identified bacterial strains could be introduced as a sufficient consortium for biodegradation of oil-contaminated soils with similar texture, which is one of the innovative aspects of this research.

Conclusion: An oil-contaminated soil sample with TPH concentration of $1640 \mathrm{mg} / \mathrm{kg}$ was subjected to bioremediation during 6 months using indigenous bacterial consortium and a TPH removal efficiency of $28.1 \%$ was obtained.

Keywords: Oil-contaminated soils, Biodegradation, Bacterial diversity, Total petroleum hydrocarbons, Indigenous bacterial consortium

Citation: Basim Y, Mohebali GH, Jorfi S, Nabizadeh R, Ahmadi Moghadam M, Ghadiri A, et al. Biodegradation of total petroleum hydrocarbons in contaminated soils using indigenous bacterial consortium. Environmental Health Engineering and Management Journal 2020; 7(2): 127-133. doi: 10.34172/EHEM.2020.15.
\end{abstract}

Article History:

Received: 12 April 2020

Accepted: 10 June 2020

ePublished: 25 June 2020

\section{Introduction}

Hydrocarbon compounds are discharged into the environment, especially to soil, through industrial petroleum-related activities such as drilling, transportation, and storage $(1,2)$.

Petroleum contaminants are harmful to the environment because they can remain in the soil pore space and stunt the growth of soil microbes, plants and animals, and can be dissolved in the soil moisture or groundwater and contaminate them, and escape into the atmosphere through volatilization (3). Therefore, environmental pollution with hydrocarbons is a great environmental concern due to their toxic nature and ubiquitous occurrence (4). Bioremediation is an effective and environmentally friendly process that degrades oil contaminants into nontoxic, simple, inorganic compounds using hydrocarbondegrading microorganisms (5). Bioremediation may remove the contaminants to a large extent and has proven successful in many applications to petroleumcontaminated soils and relies on the application of microorganism especially bacteria (6-8), which can be implemented both in situ $(9,10)$ and ex situ $(11,12)$ bioremediation technologies.

Although in situ bioremediation technologies are more 
environmentally-friendly, cheaper, and easier to perform compared to ex situ alternatives (13), but are usually longer, this drawback could be mitigated by identification and following up the quantitative variations of dominant hydrocarbon-degrading strains in polluted areas $(14,15)$. As a key question, dominant hydrocarbon-degrading strains in a highly contaminated soil were monitored and identified in order to prepare an efficient consortium for application in other polluted soils with similar soil texture. Such process is called "bioaugmentation", the inoculation of exogenous bacteria into contaminated soil (16). When contamination adversely affects the native microorganisms, bioaugmentation gives the opportunity for a successful bioremediation (17). Although bioaugmentation has been reported to be an efficient case-specific process to enhance the biodegradation of hydrocarbons in hydrocarboncontaminated soil. Therefore, if the soil texture and characteristics are known, then, there would be a bigger chance to perform a successful bioaugmentation. Consequently, identification of native hydrocarbondegrading bacteria by molecular methods provide a good understanding of the microbial community composition in polluted soils (18). This research was conducted to find the most suitable method for identifying the whole bacterial consortium. This method was applied using direct DNA extraction by $16 \mathrm{~S}$ rDNA gene sequencing during six months from oil-contaminated soils by testing a combination of many procedures, and finally, applying physical, chemical, and biochemical processes, which is one of the strength points of this study. Also, indigenous bacterial consortium was used in oil-contaminated soils without need for amplification of heterogeneous bacteria and the results showed that the identified bacterial strains could be introduced as a sufficient consortium for biodegradation of oil-contaminated soils with similar texture, which is one of the innovative aspects of this research. Furthermore, an appropriate total petroleum hydrocarbons (TPH) removal efficiency $(28.1 \%)$ in oilcontaminated soils was obtained.

\section{Materials and Methods}

\section{Materials}

For bacterial cultivation of the oil-contaminated soils in the primary stage of the study, all chemicals including hydrochloric acid $(\mathrm{HCl})$, ethanol $\left(\mathrm{C}_{2} \mathrm{H}_{5} \mathrm{OH}\right)$, acetone $\left.\left(\mathrm{CH}_{3} \mathrm{COCH}_{3}, 99.5 \%\right)\right]$, chloroform $\left(\mathrm{CHCl}_{3}, 99.5 \%\right)$, isopropanol $\left(\mathrm{C}_{3} \mathrm{H}_{8} \mathrm{O}\right)$, n-hexane $\left(\mathrm{CH}_{3}\left(\mathrm{CH}_{2}\right)_{4} \mathrm{CH}_{3}\right.$, $\geq 95.0 \%$ ), sodium hydroxide $(\mathrm{NaOH})$, phenol, sodium chloride $(\mathrm{NaCl}), \mathrm{EDTA}$, and $\mathrm{R}_{2} \mathrm{~A}$ were analytical graded and supplied by Merck company (Germany).

\section{Soil sampling}

Considering the aims of the present study, variations of $\mathrm{TPH}$ content as well as bacterial count in case and control samples were analyzed during six months. The case samples were obtained from pre-determined points due to oil leaks from oil and gas separators. Soil samples were prepared using soil cores from surface layers $(0-40 \mathrm{~cm}$ depth), which were air-dried. Soil samples were homogenized by shaking (19). Also, the same procedure was carried out in control area without TPH contamination. The conditions of sampling site for control and case samples are presented in Table 1. Sampling was performed in spring season (June) and the biodegradation in the laboratory was done during six months from August 2017 to January 2018. The study was performed in a laboratory scale and in a small pot as container with a capacity of approximately $2 \mathrm{~kg}$.

\section{DNA extraction}

Metagenomic DNA extraction was performed in a harsh manner by combining several lysis methods together. The physical lysis including bead beating with the lysis buffer treatment was done, then, the samples were applied to the enzymatic buffer and incubated with shaking overnight. The next steps for the chemical lysis and purification were continued according to Siddhapura et al (20).

Then, the genomic library was amplified by the polymerase chain reaction (PCR) using universal primers. Sequencing was carried out using the Illumina MiSeq platform at Macrogen Company of Korea, in order to examine taxonomic diversity of bacterium. Data were analyzed using QIIME software $(21,22)$.

\section{TPH measurement}

The TPH levels in the samples were determined by a gas chromatograph equipped with a flame-ionization detector (GC-FID, Chrompack CP 9001) using an HP-5 capillary column (30 m length, $0.32 \mathrm{~mm}$ inner diameter, and 0.2 $\mathrm{mm}$ film thickness). Helium was used as the carrier gas with a constant flow rate of $1 \mathrm{~mL} \mathrm{~min}^{-1}$. The temperature program was as follows: the column temperature was held at $50^{\circ} \mathrm{C}$ for 1 minute, and then, ramped to $280^{\circ} \mathrm{C}$ at $15^{\circ} \mathrm{C}$ $\mathrm{min}^{-1}$ and held for 5 minutes. The injector and detector temperatures were set at 250 and $320^{\circ} \mathrm{C}$, respectively. The injection volume was $1 \mu \mathrm{L}$. The detection limit of GC-FID was more than $10 \mathrm{ppb}$.

The obtained data were analyzed using R-Studio or $\mathrm{R}$ version 4.0.0 and SPSS version 22 .

\section{Results}

The contaminated soil was characterized as loamy sand

Table 1. The conditions of sampling site for case and control samples

\begin{tabular}{lcc}
\hline Parameters & Case & Control \\
\hline $\mathrm{pH}$ & 7.65 & 7.00 \\
Temperature of air $\left({ }^{\circ} \mathrm{C}\right)$ & 39 & 39 \\
Temperature of soil $\left({ }^{\circ} \mathrm{C}\right)$ & 35.2 & 35.2 \\
$\mathrm{EC}(\mathrm{ds} / \mathrm{m})$ & 2.7 & 2.87 \\
Age of contamination & $>6$ months & No pollution \\
Soil texture & Loamy sand & Loamy sand \\
\hline
\end{tabular}


which contained silt (22\%), clay (4\%) sand (74\%), and approximately $30 \%$ moisture content. Volatile matter content usually accounts for organic fraction of samples, which was $12 \%$ in this case. Variations of TPH content in the oil-contaminated soils are presented in Figure 1.

As shown in this figure, there is a significant difference in the removal of TPH during six months. The initial $\mathrm{TPH}$ concentration of $1640 \mathrm{mg} / \mathrm{kg}$ at the beginning of the experiments decreased to $1179 \mathrm{mg} / \mathrm{kg}$ at the end of month six $(28.1 \%$ removal). Statistical analysis showed that the mean difference in the TPH content between month zero and month six is significant at $P \leq 0.05$ (Table 2).

Diversity of bacterial strains in six continuous months and in two categories of oil-contaminated soils (case) and non-contaminated soils (control) are presented in Tables 3 and 4 , respectively.

The bacterial consortia identified in oil-contaminated soils (case) belonged to the families Halomonadaceae (91.5\%) and Bacillaceae (8.5\%). The findings are significantly different from those obtained in non-contaminated soils (control) belonging to families Entrobacteriaceae (84.6\%), Paenibacillaceae (6\%), and Bacillaceae (9.4\%). It is very surprising that the diversity of bacterial strains was less in oil-contaminated soils, and generally, the identified strains varied significantly in the case and control samples. Taxonomic diversity and frequency of bacterial community in oil-contaminated soils (case) and noncontaminated (control) soils are presented in Tables 5 and 6 , respectively.

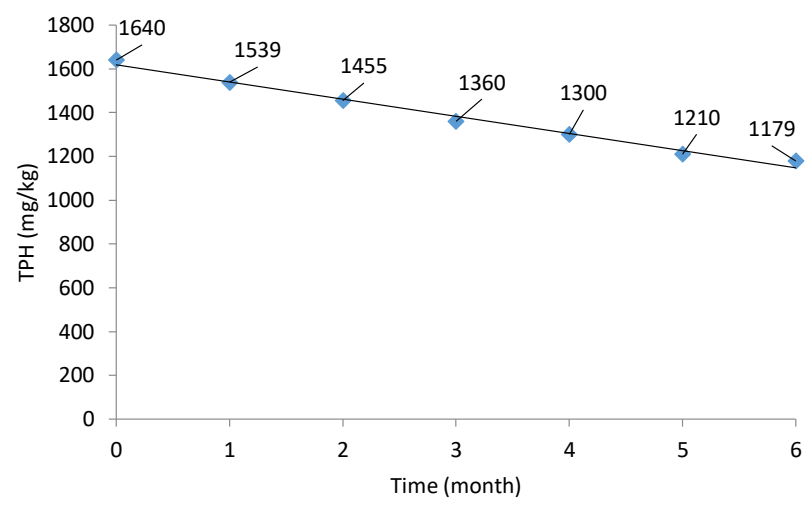

Figure 1. Variations of the TPH content in the oil-contaminated soils.
Variation of bacterial count in case and control samples during the study period are presented in Figure 2. By comparison of bacterial count changes in case and control samples, it can be concluded that there is no rational relationship between these two conditions. Generally, the total counts of bacterial consortium in control samples is smaller than the case ones.

\section{Discussion}

The statistical analysis of TPH concentration showed a significant difference in the TPH concentration in case samples at the beginning and at the end of the experiment $(P<0.05)$. By comparing the TPH removal rate $(28.1 \%)$, it can be concluded that the removal rate observed in the oil-contaminated soils can be attributed to the biodegradation activity of native microorganism (23), which is consistent with the results of some studies (24-26). Feizi et al investigated the TPH bioremediation in polluted soils using bacteria under conditions approximately similar to the present study, and reported the TPH removal efficiency of $17.7 \%$, which is similar to that reported in the present study (28.1\%) (27). Safdari et al in a study on the bioremediation of TPH, reported that the initial concentrations of TPH were reduced by $4.5 \%$ in the natural attenuation, which is very lower than that reported in the presented study. Also, they found that bioremediation by adding nutrients and bacterial consortia did not significantly enhance TPH biodegradation compared to natural attenuation, which is consistent with the results of the present study that was done without the addition of nutrients and bacterial inoculation (28). A research conducted by Liu et al in an oilfield in northern China showed that after bioremediation for 230 days, the removal efficiency of oil and grease was obtained to be $27 \%-46 \%$, which is consistent with the results of the present study. Furthermore, they reported an increase in the TPH degrader concentrations in all oily sludge, which is consistent with the results of the present study (29). The high total counts of bacterial consortium in case samples could be attributed to the occurrence of biodegradation and related growth of the bacteria compared to control samples with no pollution as a carbon source $(30,31)$. The bacterial count variations in control samples were less, which can be attributed to almost

Table 2. Results of significance test for TPH concentration between different months of study

\begin{tabular}{|c|c|c|c|c|c|c|}
\hline \multirow{2}{*}{ (I) Month } & \multirow{2}{*}{ (J) Month } & \multirow{2}{*}{ Mean Difference (I-J) } & \multirow{2}{*}{ Std. Error } & \multirow{2}{*}{$P$ value } & \multicolumn{2}{|c|}{ 95\% Confidence Interval } \\
\hline & & & & & Lower Bound & Upper Bound \\
\hline \multirow{6}{*}{6} & 0 & $-461.000^{*}$ & 60.752 & 0.003 & -742.64 & -179.36 \\
\hline & 1 & $-360.000^{*}$ & 60.752 & 0.012 & -641.64 & -78.36 \\
\hline & 2 & -276.000 & 60.752 & 0.056 & -557.64 & 5.64 \\
\hline & 3 & -181.000 & 60.752 & 0.431 & -462.64 & 100.64 \\
\hline & 4 & -121.000 & 60.752 & 1.000 & -402.64 & 160.64 \\
\hline & 5 & -31.000 & 60.752 & 1.000 & -312.64 & 250.64 \\
\hline
\end{tabular}

Dependent variable: TPH

*The mean difference is significant at $P<0.05$. 
Table 3. Average count and frequency of the bacterial community identified in the oil-contaminated soils (case)

\begin{tabular}{|c|c|c|c|}
\hline Bacterial strain & Average count & Frequency (\%) & Month \\
\hline o__Oceanospirillales; f__Halomonadaceae & 285 & 5.9 & 0 \\
\hline o__Oceanospirillales; f__Halomonadaceae; g__Halomonas; s__ & 231 & 4.8 & 0 \\
\hline o__Oceanospirillales; f__Halomonadaceae; g__Halomonas & 146 & 3.0 & 0 \\
\hline o__Oceanospirillales; f__Halomonadaceae; g__; s__ & 127 & 2.6 & 0 \\
\hline o__Bacillales; f__Bacillaceae; g__Bacillus; s__ & 141 & 2.9 & 1 \\
\hline o__Oceanospirillales; f__Halomonadaceae; g__Halomonas; s__ & 122 & 2.5 & 1 \\
\hline o__Oceanospirillales; f__Halomonadaceae & 102 & 2.1 & 1 \\
\hline o__Oceanospirillales; f__Halomonadaceae; g__Halomonas; s__ & 154 & 3.2 & 2 \\
\hline o__Oceanospirillales; f__Halomonadaceae & 132.5 & 2.8 & 2 \\
\hline o__Oceanospirillales; f__Halomonadaceae; g__Halomonas & 121 & 2.5 & 2 \\
\hline o__Oceanospirillales; f__Halomonadaceae; g__Halomonas; s__ & 252.5 & 5.2 & 3 \\
\hline o__Oceanospirillales; f__Halomonadaceae & 121.5 & 2.5 & 3 \\
\hline o__Bacillales; f__Bacillaceae; g__Bacillus; s__ & 57 & 1.2 & 3 \\
\hline o__Oceanospirillales; f__Halomonadaceae; g__Halomonas & 56 & 1.2 & 3 \\
\hline o__Oceanospirillales; f__Halomonadaceae; g__Halomonas; s__ & 1204.5 & 25.0 & 4 \\
\hline o__Oceanospirillales; f__Halomonadaceae & 542.5 & 11.3 & 4 \\
\hline o__Oceanospirillales; f__Halomonadaceae; g__Halomonas & 269.5 & 5.6 & 4 \\
\hline o__Oceanospirillales; f__Halomonadaceae; g__Halomonas; s__ & 130.5 & 2.7 & 5 \\
\hline o__Bacillales; f__Bacillaceae & 104 & 2.2 & 5 \\
\hline o__oceanospirillales; f__Halomonadaceae & 76.5 & 1.6 & 5 \\
\hline o__Oceanospirillales; f__Halomonadaceae; g__Halomonas; s__ & 190.5 & 4.0 & 6 \\
\hline o__Oceanospirillales; f__Halomonadaceae & 141.5 & 2.9 & 6 \\
\hline o__Bacillales; f__Bacillaceae; g__Bacillus; s__ & 103 & 2.1 & 6 \\
\hline Total & 4811 & 100 & - \\
\hline
\end{tabular}

Table 4. Average count and frequency of the bacterial community identified in the non-contaminated soils (control)

\begin{tabular}{|c|c|c|c|}
\hline Bacterial strain & Average Count & Frequency (\%) & Month \\
\hline o__Bacillales; f__;g_; s__ & 44 & 2.2 & 0 \\
\hline o__Bacillales; f__Bacillaceae; g__Bacillus; s_endophyticus & 20 & 1.0 & 0 \\
\hline o__Enterobacteriales; f__Enterobacteriaceae & 41.5 & 2.1 & 1 \\
\hline o__Enterobacteriales; f_Enterobacteriaceae; g__; s__ & 20 & 1.0 & 1 \\
\hline o__Enterobacteriales; f_Enterobacteriaceae; g__; s__ & 80.5 & 4.0 & 2 \\
\hline o__Enterobacteriales; f__Enterobacteriaceae & 49 & 2.5 & 2 \\
\hline o__Enterobacteriales; f__Enterobacteriaceae; g__; s__ & 500.5 & 25.1 & 3 \\
\hline o_Enterobacteriales; f__Enterobacteriaceae & 384.5 & 19.3 & 3 \\
\hline o__Enterobacteriales; f__Enterobacteriaceae & 139.5 & 7.0 & 4 \\
\hline o__Enterobacteriales; f_Enterobacteriaceae; g__ s__ & 121 & 6.1 & 4 \\
\hline o__Enterobacteriales; f_Enterobacteriaceae; g__ s__ & 134 & 6.7 & 5 \\
\hline o__Enterobacteriales; f__Enterobacteriaceae & 91 & 4.6 & 5 \\
\hline o__Bacillales; f__Paenibacillaceae; g__Paenibacillus; s__ & 122 & 6.1 & 6 \\
\hline o__Bacillales; f__Bacillaceae & 65 & 3.3 & 6 \\
\hline o__Enterobacteriales; f__Enterobacteriaceae; g__; s__ & 63.5 & 3.2 & 6 \\
\hline o_Enterobacteriales; f__Enterobacteriaceae & 59.5 & 3.0 & 6 \\
\hline o__Bacillales; f__Bacillaceae; g__Bacillus; s__ & 58 & 2.9 & 6 \\
\hline Total & 1993.5 & 100 & - \\
\hline
\end{tabular}

constant environmental conditions in terms of pollution, soil texture, and chemical composition of soil (32). For oil-contaminated soil, there is no uniform variation trend. The complicated nature of various hydrocarbons present in the contaminated soils, diversity of biodegrading bacteria with different enzymatic and metabolic functions could be considered as the possible reasons for the observed variations (33). 
Table 5. Taxonomic diversity and frequency of the bacterial community in the oil-contaminated soils (case)

\begin{tabular}{|c|c|c|c|c|c|c|}
\hline \multicolumn{6}{|c|}{ Taxonomy } & \multirow[t]{2}{*}{ Frequency (\%) } \\
\hline Kingdom & Phylum & Class & Order & Family & Genus & \\
\hline Bacteria & Proteobacteria & Gammaproteobacteria & Oceanospirillales & Halomonadaceae & Halomonas & 59.8 \\
\hline Bacteria & Proteobacteria & Gammaproteobacteria & Oceanospirillales & Halomonadaceae & - & 31.7 \\
\hline Bacteria & Firmicutes & Bacilli & Bacillales & Bacillaceae & Bacillus & 6.3 \\
\hline Bacteria & Firmicutes & Bacilli & Bacillales & Bacillaceae & - & 2.2 \\
\hline \multicolumn{6}{|c|}{ Total } & 100 \\
\hline
\end{tabular}

Table 6. Taxonomic diversity and frequency of the bacterial community in the non-contaminated soils (control)

\begin{tabular}{|c|c|c|c|c|c|c|c|}
\hline \multicolumn{7}{|c|}{ Taxonomy } & \multirow[t]{2}{*}{ Frequency (\%) } \\
\hline Kingdom & Phylum & Class & Order & Family & Genus & Species & \\
\hline Bacteria & Proteobacteria & Gammaproteobacteria & Enterobacteriales & Enterobacteriaceae & - & - & 84.6 \\
\hline Bacteria & Firmicutes & Bacilli & Bacillales & Paenibacillaceae & Paenibacillus & - & 6.0 \\
\hline Bacteria & Firmicutes & Bacilli & Bacillales & Bacillaceae & - & - & 3.3 \\
\hline Bacteria & Firmicutes & Bacilli & Bacillales & Bacillaceae & Bacillus & - & 2.9 \\
\hline Bacteria & Firmicutes & Bacilli & Bacillales & - & - & - & 2.2 \\
\hline \multirow[t]{2}{*}{ Bacteria } & Firmicutes & Bacilli & Bacillales & Bacillaceae & Bacillus & endophyticus & 1.0 \\
\hline & & & Total & & & & 100 \\
\hline
\end{tabular}

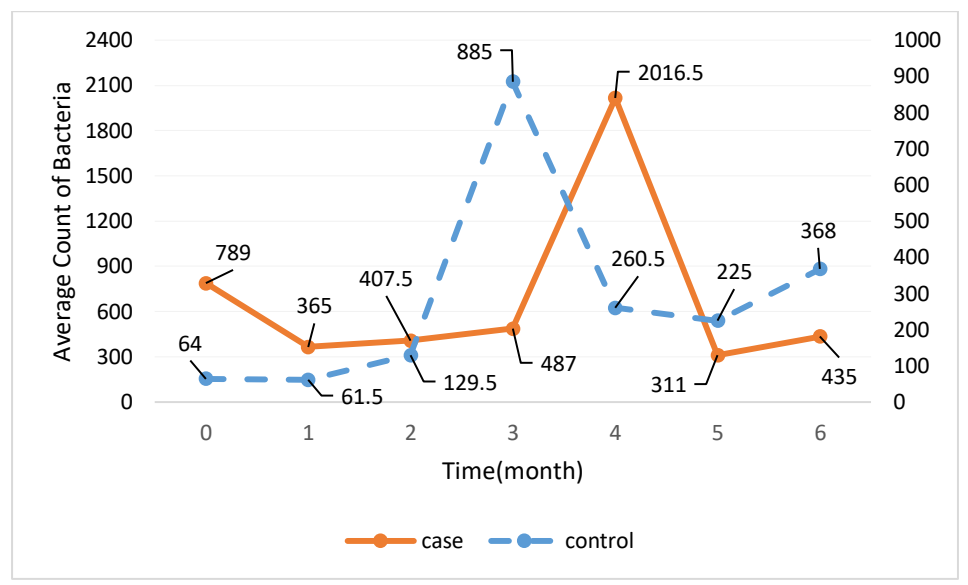

Figure 2. Variations of the average bacterial count in the case and control samples during the study period.

\section{Conclusion}

Variations of microbial count in oil-contaminated soils (case) were monitored and compared with noncontaminated soils (control). Furthermore, the bacterial strains were identified by the extraction of DNA. According to the majority of bacterial consortium in oil-contaminated soils (case) belonged to the families Halomonadaceae (91.5\%) and Bacillaceae (8.5\%). These findings are significantly different from those identified in non-contaminated soils (control) belonging to the families Entrobacteriaceae (84.6\%), Paenibacillaceae (6\%), and Bacillaceae (9.4\%). It is very surprising that the diversity of bacterial strains was less in oil-contaminated soils, and generally, the identified strains varied significantly in case and control samples. In addition, indigenous bacterial strains were identified as efficient hydrocarbon degraders with a removal efficiency of $28.1 \%$ (the initial $\mathrm{TPH}$ concentration of $1640 \mathrm{mg} / \mathrm{kg}$ ) after six months. According to the results, the identified bacterial consortium could be introduced as the efficient consortium for biodegradation of oil-contaminated soils with loamy sand texture.

\section{Acknowledgements}

This article was extracted from the $\mathrm{PhD}$ thesis of the first author (Yalda Basim). The authors would like to gratitude the Environmental Technologies Research Centre, Ahvaz Jundishapur University of Medical Sciences, for its financial support (Grant No: ETRC-9511). The ethical code was provided by the Ethics Committee of Ahvaz Jundishapur University of Medical Sciences 


\section{Ethical issues}

The authors hereby certify that all data collected during the research are as expressed in the manuscript, and no data from the study has been or will be published elsewhere separately (Ethical code: IR.AJUMS.RES.1395.254).

\section{Competing interests}

The authors declare that they have no conflict of interests.

\section{Authors' contributions}

All authors contributed in the study design, experiments, data collection and analysis, and manuscript preparation. The final version of the manuscript was reviewed and confirmed by all authors.

\section{References}

1. Ghafari S, Baboli Z, Neisi A, Mirzaee SA, Darvishi Cheshmeh Soltani R, Saeedi R, et al. Surfactant-enhanced bioremediation of $\mathrm{n}$-hexadecane-contaminated soil using halo-tolerant bacteria Paenibacillus glucanolyticus sp. strain T7-AHV isolated from marine environment. Chem Biochem Eng Q 2019; 33(1): 111-23. doi: 10.15255/ cabeq.2018.1465.

2. Varjani SJ. Microbial degradation of petroleum hydrocarbons. Bioresour Technol 2017; 223: 277-86. doi: 10.1016/j.biortech.2016.10.037.

3. Li DC, Xu WF, Mu Y, Yu HQ, Jiang H, Crittenden JC. Remediation of petroleum-contaminated soil and simultaneous recovery of oil by fast pyrolysis. Environ Sci Technol 2018; 52(9): 5330-8. doi: 10.1021/acs.est.7b03899.

4. Gupta G, Kumar V, Pal AK. Microbial degradation of high molecular weight polycyclic aromatic hydrocarbons with emphasis on pyrene. Polycycl Aromat Compd 2019; 39(2): 124-38. doi: 10.1080/10406638.2017.1293696.

5. Bajagain R, Lee S, Jeong SW. Application of persulfateoxidation foam spraying as a bioremediation pretreatment for diesel oil-contaminated soil. Chemosphere 2018; 207: 565-72. doi: 10.1016/j.chemosphere.2018.05.081.

6. Lu M, Zhang Z, Qiao W, Guan Y, Xiao M, Peng C. Removal of residual contaminants in petroleum-contaminated soil by Fenton-like oxidation. J Hazard Mater 2010; 179(1-3): 604-11. doi: 10.1016/j.jhazmat.2010.03.046.

7. Adams GO, Fufeyin PT, Okoro SE, Ehinomen I. Bioremediation, biostimulation and bioaugmention: a review. Int J Environ Bioremediat Biodegrad 2015; 3(1): 28 39. doi: 10.12691/ijebb-3-1-5.

8. Agbor RB, Antai SP, Nkanang AJ. Microbial degradation of total petroleum hydrocarbon in crude oil polluted soil ameliorated with agro-wastes. Global Journal of Earth and Environmental 2018;3(1): 1-7. doi: 10.31248/gjees2017.014.

9. Suja F, Rahim F, Taha MR, Hambali N, Rizal Razali M, Khalid A, et al. Effects of local microbial bioaugmentation and biostimulation on the bioremediation of total petroleum hydrocarbons (TPH) in crude oil contaminated soil based on laboratory and field observations. Int J Environ Bioremediat Biodegrad 2014; 90: 115-22. doi: 10.1016/j.ibiod.2014.03.006.

10. Szulc A, Ambrożewicz D, Sydow M, Ławniczak $€$, Piotrowska-Cyplik A, Marecik R, et al. The influence of bioaugmentation and biosurfactant addition on bioremediation efficiency of diesel-oil contaminated soil: feasibility during field studies. J Environ Manage 2014; 132: 121-8. doi: 10.1016/j.jenvman.2013.11.006.

11. Simpanen S, Mäkelä R, Mikola J, Silvennoinen H, Romantschuk M. Bioremediation of creosote contaminated soil in both laboratory and field scale: investigating the ability of methyl- $\beta$-cyclodextrin to enhance biostimulation. Int J Environ Bioremediat Biodegrad 2016; 106: 117-26. doi: 10.1016/j.ibiod.2015.10.013.

12. Wang SY, Kuo YC, Hong A, Chang YM, Kao CM. Bioremediation of diesel and lubricant oil-contaminated soils using enhanced landfarming system. Chemosphere 2016; 164: 558-67. doi: 10.1016/j.chemosphere.2016.08.128.

13. Rezaei Kalantary R, Mohseni-Bandpi A, Esrafili A, Nasseri S, Rashid Ashmagh F, Jorfi S, et al. Effectiveness of biostimulation through nutrient content on the bioremediation of phenanthrene contaminated soil. J Environ Health Sci Eng 2014; 12(1): 143. doi: 10.1186/ s40201-014-0143-1.

14. Ahmadi M, Jorfi S, Kujlu R, Ghafari S, Darvishi Cheshmeh Soltani R, Jaafarzadeh Haghighifard N. A novel salt-tolerant bacterial consortium for biodegradation of saline and recalcitrant petrochemical wastewater. J Environ Manage 2017; 191: 198-208. doi: 10.1016/j.jenvman.2017.01.010.

15. Bao YJ, Xu Z, Li Y, Yao Z, Sun J, Song H. High-throughput metagenomic analysis of petroleum-contaminated soil microbiome reveals the versatility in xenobiotic aromatics metabolism. J Environ Sci (China) 2017; 56: 25-35. doi: 10.1016/j.jes.2016.08.022.

16. Jorfi S, Rezaee A, Mobeh-Ali GA, Jaafarzadeh Haghighifard N. Application of biosurfactants produced by Pseudomonas aeruginosa SP4 for bioremediation of soils contaminated by pyrene. Soil Sediment Contam 2013; 22(8): 890-911. doi: 10.1080/15320383.2013.770439.

17. Jorfi S, Samaei MR, Darvishi Cheshmeh Soltani R, Talaie Khozani A, Ahmadi M, Barzegar G, et al. Enhancement of the bioremediation of pyrene-contaminated soils using a hematite nanoparticle-based modified fenton oxidation in a sequenced approach. Soil Sediment Contam 2017; 26(2): 141-56. doi: 10.1080/15320383.2017.1255875.

18. Zhang H, Feng J, Chen S, Zhao Z, Li B, Wang Y, et al. Geographical patterns of nirS gene abundance and nirS-type denitrifying bacterial community associated with activated sludge from different wastewater treatment plants. Microb Ecol 2019; 77(2): 304-16. doi: 10.1007/s00248-018-1236-7.

19. Kalantary RR, Badkoubi A, Mohseni-Bandpi A, Esrafili A, Jorfi S, Dehghanifard E, et al. Modification of PAHs biodegradation with humic compounds. Soil Sediment Contam 2013; 22(2): 185-98. doi: 10.1080/15320383.2013.722139.

20. Siddhapura PK, Vanparia S, Purohit MK, Singh SP. Comparative studies on the extraction of metagenomic DNA from the saline habitats of Coastal Gujarat and Sambhar Lake, Rajasthan (India) in prospect of molecular diversity and search for novel biocatalysts. Int J Biol Macromol 2010; 47(3): 375-9. doi: 10.1016/j.ijbiomac.2010.06.004.

21. Caporaso JG, Kuczynski J, Stombaugh J, Bittinger K, Bushman FD, Costello EK, et al. QIIME allows analysis of high-throughput community sequencing data. Nat 
Methods 2010; 7(5): 335-6. doi: 10.1038/nmeth.f.303.

22. Lawley B, Tannock GW. Analysis of 16S rRNA gene amplicon sequences using the QIIME software package. Methods Mol Biol 2017; 1537: 153-63. doi: 10.1007/978-14939-6685-1_9.

23. Arash Asadirad $\mathrm{MH}$, Mazaheri Assadi M, Rashedi $\mathrm{H}$, Nejadsattari T. Effects of indigenous microbial consortium in crude oil degradation: a microcosm experiment. Int J Environ Res 2016; 10(4): 491-8. doi: 10.22059/ ijer.2016.59603.

24. Margesin R, Hämmerle M, Tscherko D. Microbial activity and community composition during bioremediation of diesel-oil-contaminated soil: effects of hydrocarbon concentration, fertilizers, and incubation time. Microb Ecol 2007; 53(2): 259-69. doi: 10.1007/s00248-006-9136-7.

25. Pourfadakari S, Ahmadi M, Jaafarzadeh N, Takdastan A, Neisi AA, Ghafari S, et al. Remediation of PAHs contaminated soil using a sequence of soil washing with biosurfactant produced by Pseudomonas aeruginosa strain PF2 and electrokinetic oxidation of desorbed solution, effect of electrode modification with $\mathrm{Fe} 3 \mathrm{O} 4$ nanoparticles. J Hazard Mater 2019; 379: 120839. doi: 10.1016/j. jhazmat.2019.120839.

26. Wu M, Dick WA, Li W, Wang X, Yang Q, Wang T, et al. Bioaugmentation and biostimulation of hydrocarbon degradation and the microbial community in a petroleumcontaminated soil. Int Biodeterior Biodegradation 2016; 107: 158-64. doi: 10.1016/j.ibiod.2015.11.019.

27. Feizi R, Jorfi S, Takdastan A. Bioremediation of phenanthrene-polluted soil using Bacillus kochii AHVKH14 as a halo-tolerant strain isolated from compost. Environ Health Eng Manag 2020; 7(1): 23-30. doi: 10.34172/ ehem.2020.04.

28. Safdari MS, Kariminia HR, Rahmati M, Fazlollahi F, Polasko A, Mahendra S, et al. Development of bioreactors for comparative study of natural attenuation, biostimulation, and bioaugmentation of petroleum-hydrocarbon contaminated soil. J Hazard Mater 2018; 342: 270-8. doi: 10.1016/j.jhazmat.2017.08.044.

29. Liu W, Luo Y, Teng Y, Li Z, Christie P. Prepared bed bioremediation of oily sludge in an oilfield in northern China. J Hazard Mater 2009; 161(1): 479-84. doi: 10.1016/j. jhazmat.2008.03.123.

30. Liu PW, Chang TC, Chen CH, Wang MZ, Hsu HW. Effects of soil organic matter and bacterial community shift on bioremediation of diesel-contaminated soil. Int Biodeterior Biodegradation 2013; 85: 661-70. doi: 10.1016/j. ibiod.2013.01.010.

31. Zhang J, Zhao R, Cao L, Lei Y, Liu J, Feng J, et al. Highefficiency biodegradation of chloramphenicol by enriched bacterial consortia: kinetics study and bacterial community characterization. J Hazard Mater 2020; 384: 121344. doi: 10.1016/j.jhazmat.2019.121344.

32. Abrusci C, Pablos JL, Marín I, Espí E, Corrales T, Catalina F. Comparative effect of metal stearates as pro-oxidant additives on bacterial biodegradation of thermal- and photo-degraded low density polyethylene mulching films. Int Biodeterior Biodegradation 2013; 83: 25-32. doi: 10.1016/j.ibiod.2013.04.002.

33. Singh S, Kumar V, Singh J. Kinetic study of the biodegradation of glyphosate by indigenous soil bacterial isolates in presence of humic acid, $\mathrm{Fe}(\mathrm{III})$ and $\mathrm{Cu}(\mathrm{II})$ ions. J Environ Chem Eng 2019; 7(3): 103098. doi: 10.1016/j. jece.2019.103098. 